\title{
AKTIVITAS ANTIOKSIDAN AIR BUAH BERUWAS LAUT (Scaevola taccada)
}

\section{Azwin Apriandi*, Zubaidah Anjar Rezeki, Kiki Fatmawati, Sri Novalina Amrizal, R. Marwita Sari Putri}

Program Studi Teknologi Hasil Perikanan Fakultas Ilmu Kelautan dan Perikanan Universitas Maritim Raja Ali Haji

Diterima: 2 Agustus 2021/Disetujui: 29 Oktober 2021

${ }^{\star}$ Korespondensi: azwinapriandi@gmail.com

Cara sitasi: Apriandi A, Rezeki ZA, Fatmawati K, Amrizal SN, Putri RMS. 2021. Aktivitas antioksidan air buah beruwas laut (Scaeveola taccada). Jurnal Pengolahan Hasil Perikanan Indonesia. 24(3): 325-329.

\begin{abstract}
Abstrak
Scaevola taccada adalah salah satu tanaman yang banyak dijumpai di pesisir pantai yang berpasir di daerah tropis. Tanaman ini secara empiris banyak memiliki manfaat kesehatan oleh masyarakat pesisir. Penelitian ini bertujuan untuk menganalisis aktivitas antioksidan dan vitamin $C$ yang terdapat pada air buah beruwas laut. Metode penelitan berupa pengujian karakterisasi dan pengukuran morfometrik, serta aktivitas antioksidan ekstrak menggunakan metode DPPH. Hasil penelitian data rendemen yaitu 2,84\% air buah muda, 97,16\% ampas buah muda, 40,37\% air buah tua, dan 59,63\% ampas buah tua. Aktivitas antioksidan $\mathrm{IC}_{50}$ adalah air buah tua $113,47 \mathrm{ppm}$, air buah muda 130,71 ppm, air buah campuran 164,58 ppm. Pengujian kadar vitamin C air buah tua 7,04 mg, air buah muda 36,96 mg, air buah campuran 30,8 mg.
\end{abstract}

Kata kunci: antioksidan, Scaevola taccada, vitamin C

\section{Antioxidant Activities of Beach Naupaka's Water (Scaevola taccada)}

\begin{abstract}
Scaevola taccada (Beach Naupaka) is common plant found on Indonesia coast.This study was aimed to determine antioxidant activity and levels of vitamin $\mathrm{C}$ contained in the juice of old, young, and mixed beach naupaka's fruit. Antioxidant activity was tested using DPPH method and vitamin C levels using the iodimetric titration $\mathrm{m}$. The results obtained showed that the antioxidant activity of beach naupaka were $113.47 \mathrm{ppm}$ for old fruit, $130.71 \mathrm{ppm}$ for young fruit, $164.58 \mathrm{ppm}$ for mixed fruit. Vitamin C levels of old, young, and mixed fruit water were $7.04 \mathrm{mg}, 36.96 \mathrm{mg}$, and $30.8 \mathrm{mg}$ respectively.
\end{abstract}

Keyword: antioxidant, Scaevola taccada, vitamin C 


\section{PENDAHULUAN}

Radikal bebas dikenal juga dengan molekul yang memiliki elektron bebas. Elektron bebas ini akan mengganggu molekul netral. Jika gangguan ini terjadi secara kontinu di dalam tubuh manusia maka akan menimbulkan efek negatif terhadap kesehatan (Werdhasari 2014). Gangguan dari radikal bebas dapat dihambat dengan antioksidan (Rahmawati et al. 2014). Risiko penyakit yang timbul akibat radikal bebas dapat dikurangi dengan mengonsumsi makanan atau minuman yang mengandung antioksidan (Pardede 2018). Antioksidan dapat berasal dari sumber alami berupa buah-buahan dan sayuran maupun yang berasal dari bahan sintetik (Kumar 2011; Bahriul et al. 2014; Nurjanah et al. 2014).

Buah beruwas laut (Scaevola taccada) merupakan sumber alami tanaman pesisir yang berpotensi sebagai sumber antioksidan. Rudianto et al. (2019) menyatakan bahwa ekstrak metanol dan kloroform beruwas laut memiliki aktivitas antioksidan yang sangat kuat. Beruwas laut merupakan tanaman pesisir tumbuh di tanah pasir berkerikil dan berfungsi sebagai pencegah erosi pantai, berbentuk rumpun bergerombol dengan ukuran tinggi mencapai $4 \mathrm{~m}$ (Sutar et al. 2017). Masyarakat pesisir memanfaatkan tanaman ini untuk obat-obatan di antaranya obat tetes telinga dan tetes mata, malaria, sipilis, disentri, beri-beri serta penyakit kulit (Dahlia et al. 2013). Penelitian ini bertujuan untuk menganalisis kandungan antioksidan dari air buah beruwas laut tua dan muda.

\section{BAHAN DAN METODE Bahan dan Alat}

Bahan utama yang digunakan dalam penelitian ini adalah buah beruwas laut tua dan muda. Bahan yang digunakan untuk pengujian antioksidan berupa DPPH (1,1-difenil-2pikrilhydrazil) Sigma Aldrich, metanol p.a (MERCK), sedangkan bahan untuk pengujian kadar vitamin $C$ adalah akuades, yodium 0,01 $\mathrm{N}$ (Polylab), Natrium tiosulfat 0,1 N (ROFA), dan amilum 1\% (Milipore).

Alat yang digunakan dalam penelitian ini adalah aluminium foil, cawan uji, gelas beker, tabung reaksi, buret, corong pemisah, labu erlenmeyer, timbangan analitik (OSUKA FA2004E), mikro pipet (SL-1000), vortex Gilson, dan spektrofotometer (UV-1800).

\section{Metode}

Penelitian ini terdiri dari karakterisasi dan pengukuran morfometrik, pengujian aktivitas antioksidan ekstrak menggunakan metode DPPH (1,1-difenil-2-pikrilhidrazil) untuk air buah tua, buah muda, dan air buah campuran beruwas laut dan pengujian kadar vitamin $\mathrm{C}$ menggunakan titrasi iodometri.

\section{Karakterisasi}

Pengamatan morfologi dilakukan dengan metode deskriptif dengan pengamatan dan pengukuran terhadap bentuk, ukuran, dan jumlah karakter-karakter yang diamati. Bagian yang diamati adalah buah muda dan buah tua (bentuk buah, ukuran, dan warna buah).

\section{Rendemen}

Rendemen merupakan persentase perbandingan antara berat bagian bahan yang dapat dimanfaatkan dengan berat total bahan. Rendemen buah beruwas laut dihitung menggunakan rumus :

Rendemen $=\frac{\text { bobot contoh }(\mathrm{g})}{\text { bobot total }(\mathrm{g})} \times 100 \%$

\section{Ekstraksi}

Proses ekstraksi dilakukan dengan cara $1 \mathrm{~kg}$ buah beruwas laut muda dan tua dalam keadaan segar diperas hingga mendapatkan filtrat. Filtrat yang diperoleh berbentuk cairan dijadikan sebagai ekstrak kasar. Hasil ekstraksi berupa cairan disimpan di dalam botol. Setelah itu dilakukan perhitungan rendemen dari hasil ekstraksi dan dilakukan pengujian.

\section{Analisis antioksidan (Molyneux 2004)}

Uji aktivitas antioksidan ekstrak air buah beruwas laut dilakukan menggunakan metode DPPH pada konsentrasi 200, 400, dan 600 ppm. Vitamin C digunakan sebagai pembanding dan kontrol positif. Larutan DPPH dibuat dengan melarutkan kristal DPPH ke dalam pelarut methanol p.a dengan konsetrasi $1 \mathrm{mM}$. Masing- masing sampel diambil 4,5 mL dan direaksikan dengan $500 \mu \mathrm{L}$ larutan DPPH $1 \mathrm{mM}$ dalam tabung reaksi yang 
berbeda. Larutan kemudian ditutup dengan alminium foil dan disimpan pada ruangan gelap selama 30 menit. Absorbansi diukur dengan menggunakan spektrofotometer UV-VIS pada panjang gelombang $517 \mathrm{~nm}$. Aktivitas antioksidan masing-masing sampel dinyatakan dengan persentase penghambatan radikal bebas yang dihitung dengan rumus:

Inhibisi $(\%)=\frac{\text { absorbansi kontrol-absorbansi sampel }}{\text { absorbansi kontrol }} \quad \mathrm{x} 100 \%$

Nilai konsetrasi dan hambatan ekstrak diplot masing-masing pada sumbu $\mathrm{x}$ dan $\mathrm{y}$. pada persamaan regresi linear untuk mencari nilai $\mathrm{IC}_{50}$.

\section{Analisis kadar vitamin C (Modifikasi El-Ishaq dan Obirinakem 2015)}

Pengamatan kadar vitamin C ditentukan secara titrasi. Sebanyak $20 \mathrm{~mL}$ sampel dimasukkan ke dalam labu $100 \mathrm{~mL}$ dan ditambahkan akuades hingga tepat tanda batas. Kemudian dimasukkan ke dalam labu erlenmeyer $25 \mathrm{~mL}, 5 \mathrm{~mL} \mathrm{H}_{2} \mathrm{SO}_{4} 2 \mathrm{~N}$, dan 5 tetes indikator amilum $1 \%$, kemudian dititrasi dengan yodium $\left(\mathrm{I}_{2}\right) \quad 0,01 \mathrm{~N}$ sampai timbul warna biru. Kandungan vitamin $\mathrm{C}$ dapat dihitung dengan rumus:

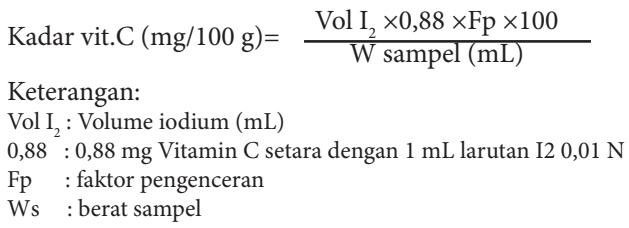

\section{Analisis data}

Data hasil penelitian dianalisis menggunakan metode deskriptif menggunakan perangkat lunak Microsoft Excel 2010.

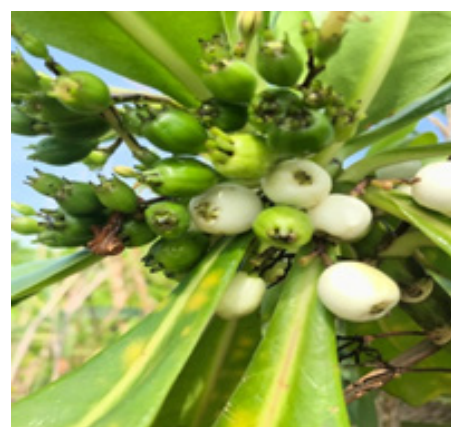

Figure 1 Fruit of Beach Naupaka

\section{HASIL DAN PEMBAHASAN Karakteristik Beruwas Laut}

Beruwas laut merupakan tanaman pesisir yang berbentuk gundukan bulat serta memiliki daun berwarna hijau kekuningan, dan buah berwarna putih (Rudianto et al. 2019). Pengamatan morfologi buah beruwas laut terlihat buah berbentuk bulat tidak sempurna dan sedikit melonjong, berwarna putih susu, air perasan berwarna putih sedikit kuning keruh, berdiameter samping 375,1 $\mathrm{mm}$ dan diameter berdiri $332,5 \mathrm{~mm}$. Tekstur daging lembut dan terdapat biji yang keras berwarna putih kecokelatan ketika buah sudah tua. Ketika buah masih muda, buah berwarna hijau, air perasan buah berwarna hijau, berdiameter samping $367,5 \mathrm{~mm}$ dan berdiameter berdiri $276,8 \mathrm{~mm}$, serta terdapat biji berwarna putih keras. Gambar tanaman beruwas laut dapat diamati pada Figure 1.

Rendemen buah beruwas laut merupakan salah satu data penting untuk mengarakterisasi tanaman ini. Hasil pengukuran dapat dilihat pada Figure 2.

Pengukuran rendemen menunjukkan terdapat 2,84\% air buah muda, $97,16 \%$ ampas, $40,37 \%$ air buah tua, dan 59,63\% ampas buah tua. Pengaruh perbedaan pada rendeman buah tua dan muda dipengaruhi oleh tingkat kematangan buah, berat, dan ukuran buah (Pamungkas et al. 2019). Tinggi rendahnya kadar air ini berhubungan dengan daya ikat air. Air bebas dapat dikeluarkan dari dalam buah dengan perlakuan fisik, sehingga air yang tetap tinggal dalam daging adalah air yang terikat erat dan air yang tidak bergerak atau air terikat. Semakin muda buah, maka tekstur daging buah semakin keras karena lebih banyak air terikat dibandingkan air bebas. Oleh karena itu rendemen air buah

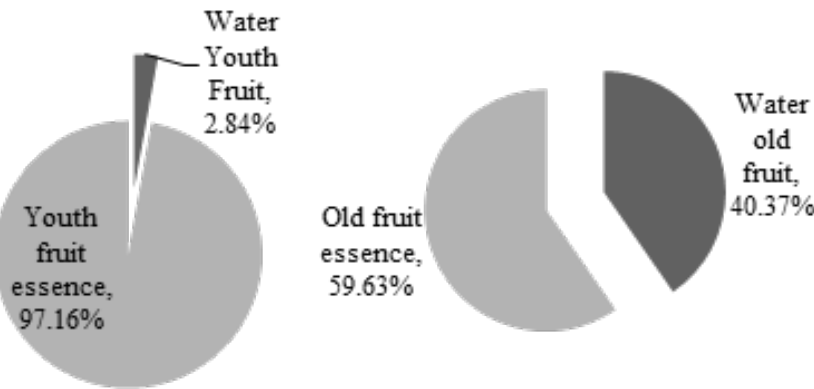

Figure 2 Yield of Beach Naupaka 
muda lebih sedikit jika dibandingkan dengan buah tua.

\section{Analisis Antioksidan}

Pengujian antioksidan dilakukan dengan metode DPPH. Penggunaan metode ini didasarkan pada teknis kerja yang sederhana, mudah, cepat, dan tidak memerlukan sampel banyak. Prinsip kerja metode ini adalah mengukur $\mathrm{IC}_{50}$ yang dibutuhkan untuk menangkap radikal DPPH sebanyak 50\% (Wanita et al. 2018). Hasil analisis antioksidan ekstrak air buah beruwas laut dapat dilihat pada Table 1.

Table 1 Antioxidant activities of beach naupaka's water

\begin{tabular}{lrl}
\hline \multicolumn{1}{c}{ Sample } & $\mathrm{IC}_{50}$ & $\begin{array}{c}\text { Antioxidant } \\
\text { level }\end{array}$ \\
\hline Old fruit & 113.47 & Middle \\
Young fruit & 130.71 & Middle \\
Mix fruits & 164.58 & Low \\
Vitamin C & 2.72 & Very strong \\
\hline Note: ${ }^{*}$ Dahliat et al. 2019 &
\end{tabular}

Table 1 menunjukkan bahwa ekstrak air buah beruwas laut memiliki aktivitas antioksidan sedang pada ekstrak air buah tua dengan nilai $\mathrm{IC}_{50} 113,47 \mathrm{ppm}$, dan air buah muda memiliki nilai $\mathrm{IC}_{50} 130,71 \mathrm{ppm}$, sedangkan pada ekstrak air buah campuran memiliki aktivitas antioksidan lemah dengan nilai IC I0 $_{164,58}$ ppm. Semakin kecil nilai IC $_{50}$ maka aktivitas antioksidannya semakin tinggi (Purwanto et al. 2017).

Table 1 menunjukkan ekstrak buah tua dan muda memiliki nilai $\mathrm{IC}_{50}<150$. Ekstrak air buah tua memiliki aktivitas antioksidan sedang. Akan tetapi vitamin C tetap memiliki aktivitas antioksidan lebih baik dari ekstrak air buah beruwas laut. Berdasarkan penelitian Rudianto et al. (2019) aktivitas antioksidan ekstrak metanol buah beruwas laut memiliki nilai $\mathrm{IC}_{50} 0,47$ dan ekstrak kloroform $\mathrm{IC}_{50} 0,46$. Hal ini terjadi karena penggunaan pelarut pada saat ekstraksi memengaruhi kandungan bioaktif yang terdapat pada buah uji. Sebagai perbandingan, ekstrak buah nipah memiliki nilai $\mathrm{IC}_{50} 415,00 \mathrm{ppm}$ (Imra et al. 2016).
Berdasarkan hal ini Rudianto et al. (2019) menyatakan bahwa beruwas laut memiliki kandungan aktif berupa flavonoid. Senyawa flavonoid merupakan senyawa yang berfungsi sebagai anti inflamasi dan antioksidan, antibakteri, antihipertensi, dan sitotoksik (Patil dan Jadhav 2013; Gafur et al. 2011).

\section{Analisis Kadar Vitamin C}

Hasil analisis kadar vitamin C pada air buah beruwas laut dapat dilihat pada Table 2 .

Table 1 Vitamin $C$ of beach naupaka's water

\begin{tabular}{lr}
\hline \multicolumn{1}{c}{ Sample } & \multicolumn{1}{c}{ Vitamin C } \\
\hline Old fruit & 7.04 \\
Young fruit & 36.96 \\
Mix fruits & 30.8 \\
\hline
\end{tabular}

Pengukuran vitamin C menggunakan metode titrasi iodimetri (Damayanti dan Kurniawan 2017). Prinsip kerja metode uji ini yaitu vitamin $\mathrm{C}$ akan bereaksi dengan iodin kemudian akan terjadi perubahan warna menjadi biru (Karmila dan Nuryanti 2021). Berdasarkan hasil analisis vitamin C, ekstrak air buah beruwas laut tua, muda, dan campuran berturut-turut adalah $7,04 \mathrm{mg} / 100 \mathrm{~g}, 36,96$ $\mathrm{mg} / 100 \mathrm{~g}$, dan 30,8 mg/100 g. Kandungan vitamin Cpada ekstrak air buah muda memiliki nilai tertinggi. Semakin matang buah maka kandungan air dan tekstur meningkat, tetapi vitamin C semakin menurun (Susanti 2012). Hasil penelitian Pamungkat et al. (2019) kadar vitamin $\mathrm{C}$ pada buah beruwas laut adalah $22,578 \mathrm{mg}$, buah ara $4,13 \mathrm{mg}$, dan buah markisa 5,16 mg. Sedangkan pada penelitian Karmila et al. (2021) buah rambusa (Passiflora foetida) mentah memiliki kandungan vitamin C 1,31 mg dan buah matang 2,21 mg. Ekstrak air buah beruwas laut memiliki kandungan vitamin $\mathrm{C}$ lebih baik dibandingkan dengan jenis buah markisa, ara, dan rambusa.

\section{KESIMPULAN}

Ekstrak air buah beruwas laut memiliki aktivitas antioksidan. Pada pengujian aktivitas antioksidan ekstrak air buah tua memiliki nilai yang paling baik. Pada analisis kadar vitamin C pada air buah tua lebih sedikit dari buah muda dan air buah campuran memiliki nilai pertengahan. 


\section{UCAPAN TERIMA KASIH}

Terimakasih diucapkan kepada Lembaga Penelitian pengabdian Kepada Masyarakat dan Penjaminan Mutu (LP3M) Universitas Maritim Raja Ali Haji atas pembiayaan hibah Penelitian Unggulan Prodi (PUP) tahun anggaran 2021.

\section{DAFTAR PUSTAKA}

Bahriul P, Rahman N, Diah AWM. 2014. Uji aktivitas antioksidan ekstrak daun salam (Syzygium polyanthum) dengan menggunakan 1,1-difenil-2pikrilhidrazil. Jurnal Akademika Kimia. 3(3): 143-149.

Dahlia AA, Kosman R, Halija. 2013. Uji aktivitas antiradical bebas fraksi dietil eter beruwas laut (Scaevola taccada (Gaertn.) Roxb.) menggunakan DPPH. As-Syifaa. 5 (1) : 62-71.

Damayanti ET, Kurniawati P. 2017. Perbandingan metode penentuan vitamin $C$ pada minuman kemasan menggunakan metode spektrofotometer Uv-Vis dan iodimetri. Prosiding Seminar Nasional Kimia dan Pembelajaran. 258-266.

El-Ishaq A, Obirinakem S. 2015. Effect of temperature and storage on vitamin $\mathrm{C}$ content in fruits juice. International Journal Of Chemical and Biomolecular Science.1(2):17-21.

Gafur MA, Isa I, Bialangi N. 2011. Isolasi dan identifikasi senyawa flavonoid dari daun jamblang (Syzgium cumini). Jurusan Kimia Fakultas MIPA Universitas Negeri Gorontalo.

Imran, Tarman K, Desniar. 2016. Aktivitas antioksidan dan antibakteri ekstrak nipah (Nypa fruticans) terhadap Vibrio sp. isolat kepiting bakau (Scylla sp.). Jurnal Pengolahan Hasil Perikanan Indonesia. 19(3): 241-250.

Karmila, Nuryanti S. 2021. Analisis vitamin C pada buah rambusa (Passiflora foetida L.). Jurnal Media Eksakta. 17(1): 46-51.
Molyneux, P. 2004. The use of the stable free radical diphenylpicryl-hydrazyl (DPPH) for estimating antioxidant activity.

Nurjanah, Abdullah A, Apriandi A. 2011. Aktifitas antioksidan dan komponen bioaktif keong ipong-ipong (Fasciolaria salmo). Jurnal Pengolahan Hasil Perikanan Indonesia. 11(1): 22-29.

Pamungkas AN, Apriandi A, Suhandana M. 2019. Analisis kandungan vitamin dan mineral dari buah beruwas laut (Scaevola taccada). Marinade. 02(02): 30-46.

Purwanto D, Bahri S, Ridhay A. 2017. Uji aktivitas antioksidan ekstrak buah purnajiwa (Kopsia arborea Blume.) dengan berbagai pelarut. Jurnal Riset Kimia Kovalen. 3(1): 24-32.

Rahmawati, Rahman S, Wati A, Herman H, Arsyad F. 2014. Test of antiokxidan activity leaves of Scaevola taccada (Gaertn.) Roxb. using DPPH (1,1-Diphenyl-2Picrylhydrazyl). International Research Jounal of Pharmcy. 5(3): 159-162.

Rudianto, Putri RMS, Apriandi A. 2019. Aktivitas antioksidan dari tanaman beruas laut (Scaevola taccada). Marinade. 02(01): 29-38.

Susanti D. 2012. Variasi temperatur dan waktu tahan kalsinasi terhadap unjuk kerja semikonduktor $\mathrm{TiO}_{2}$ sebagai dssc dengan dye dari ekstrak buah naga merah. Jurnal Teknik. 1(1): 2301-2308.

Sutar NG, Kulkarni A, Arangale KB. 2017. Literature review of (Scaevola taccada). Journal of Pharmaceutical Research. 5(11): 231-237.

Wanita D, Rusmini, Ashfia F, Adriane FY. 2018. Uji aktivitas antioksidan ekstrak etanol daun beluntas (Pluchea indica L.) dengan metode DPPH (2, 2-Difenil1Pikrilhidrazil). Indonesian Chemistry and Aplication Journal. 2(2): 25-28.

Werdhasari A. 2014. Peran antioksidan bagi kesehatan. Jurnal Biotek Medisiana Indonesia/ 3(2): 59-68. 